\title{
Differential Effects of Dorsal and Ventral Hippocampal Lesions
}

\author{
Brian J. Hock, Jr. and Michael D. Bunsey \\ Kent State University, Kent, Ohio, 44242
}

Several studies have demonstrated that dorsal, but not ventral, hippocampus is critical for spatial memory. The mnemonic role of the ventral hippocampus remains unclear. The existence of relatively direct connections between hypothalamic nuclei and ventral hippocampus suggests that the ventral hippocampus may be involved in acquisition of information regarding internal cues (e.g., hunger).

Male Long-Evans rats received ibotenic acid-induced lesions of either dorsal or ventral hippocampus or underwent sham surgeries. After a 3 week recovery, subjects were tested on delayed alternation in a T-maze and on a task in which fooddeprivation state was used as a contextual cue (Davidson and Jarrard, 1993). Rats with dorsal, but not ventral, lesions were impaired in delayed alternation, consistent with previous findings, but both groups were impaired in the learning of the internal state-shock association task.

Key words: ventral hippocampus; dorsal hippocampus; ibotenic lesions; T-maze; food deprivation; spatial memory
Several recent studies have examined functional dissociations between dorsal and ventral hippocampus. Moser et al. (1993, $1995)$ reported that lesions of dorsal hippocampus (DH), but not ventral hippocampus (VH), caused spatial memory impairments in rats. These results are broadly consistent with electrophysiological data which have indicated that, in comparison with $\mathrm{VH}$, DH contains both a greater proportion of and more sharply tuned place cells (Jung et al., 1994). Together, these results suggest a functional dissociation along the septotemporal extent of the hippocampus, with the dorsal hippocampus being more important than ventral hippocampus for spatial memory processes.

However, the above lesion studies are limited, because they did not demonstrate a double dissociation between $\mathrm{DH}$ and $\mathrm{VH}$. Demonstration of a double dissociation is critical to confidently conclude that the spatial deficit that follows a $\mathrm{DH}$ lesion reflects a preferential role of $\mathrm{DH}$ in spatial memory; based on the above results, we cannot rule out the possibility that $\mathrm{DH}$ lesions are merely more disruptive than $\mathrm{VH}$ lesions. According to this latter framework, DH lesions would be more likely to disrupt any form of hippocampal-dependent memory. Notably, demonstration of a double dissociation between $\mathrm{DH}$ and $\mathrm{VH}$ would also provide insight into the functional role of $\mathrm{VH}$, about which little is presently known.

The present study tested for a double dissociation between $\mathrm{DH}$ and VH lesions using two tasks: (1) a spatial delayed alternation task, and (2) a conditional learning task that used internal state as a contextual cue. $\mathrm{DH}$ rats, but not $\mathrm{VH}$ rats, were expected to demonstrate an impairment in the spatial task, as in previous studies, whereas $\mathrm{VH}$ rats were expected to demonstrate an impairment in the internal state task. Davidson and Jarrard (1993) have shown previously that specific hippocampal lesions (encompassing both $\mathrm{DH}$ and $\mathrm{VH}$ ) cause impairments in the internal state-conditional task. A preferential role for the $\mathrm{VH}$ in this type of task was hypothesized based on neuroanatomical consider-

\footnotetext{
Received March 5, 1998; revised June 15, 1998; accepted June 18, 1998.

This work was supported by National Institutes of Health FIRST Award R29 N536962-01 (M.D.B.). We thank Dr. Doug Kline for assistance with photography.

Correspondence should be addressed to Michael Bunsey or Brian Hock, 118 Kent Hall, Kent State University, Kent, OH 44242.

Copyright (ㄷ) 1998 Society for Neuroscience $\quad 0270-6474 / 98 / 187027-06 \$ 05.00 / 0$
}

ations. VH receives a relatively dense input from the tuberomammillary nucleus in the posterior hypothalamus (Kohler et al., 1985), which presumably carries information regarding internal states, including hunger (Risold and Swanson, 1996).

\section{MATERIALS AND METHODS}

Subjects. Thirty-six naive male Long-Evans rats (Charles River Laboratories, Wilmington, MA) were kept on a 15/9 hr light/dark cycle. Animals were housed in Plexiglas home cages and given water ad libitum. Food, however, was limited according to task (see below).

Surgery and histology. The surgical procedure was the same technique developed by Jarrard (1989), using multiple microinjections of ibotenic acid (Sigma, St. Louis, MO). Rats were anesthetized with pentobarbital $(50 \mathrm{mg} / \mathrm{kg})$ and placed into a stereotaxic frame. A midline incision was made on the scalp, the skin was reflected, and the skull overlying the targeted region was removed. Injections of ibotenic acid, dissolved in PBS, $\mathrm{pH} 7.4$, at $10 \mathrm{mg} / \mathrm{ml}$, were given using a $2 \mu \mathrm{l}$ Hamilton syringe with a fine pipette attachment to minimize mechanical damage mounted on the stereotaxic frame. Injections of $0.05-0.1 \mu \mathrm{l}$ were given over a 30-60 sec delivery period at various points, depending on the type of lesion (Table 1). Rats in the sham group underwent all of the surgical procedures, except that neurotoxin was not released and the pipette did not enter the hippocampal region. Rats were given 3 weeks to recover before training began.

After testing, rats were given an overdose of pentobarbital and perfused with physiological saline and $10 \%$ formal saline. The brains were placed in a formal saline solution, followed by a sucrose-formalin solution for at least $24 \mathrm{hr}$ each. The brains were then sectioned $(40 \mu \mathrm{m})$ in the coronal plane and stained with cresyl violet. Lesion extent was calculated by using a point-counting technique (Gunderson and Jensen, 1987). For each of three evenly spaced sections through the dorsal half of the hippocampus, an array of dots was placed directly over the section, and the number of points falling on hippocampal tissue was counted. The volume of intact tissue for each region was calculated by multiplying the sum of the areas among the sections by the distance between the sections. The values for each subject were subtracted from the value of control values to estimate percent of damage. This procedure was repeated for $\mathrm{VH}$.

Apparatus and procedure. During the last week of the 3 week recovery period, each rat was handled. Most of the subjects (see below) were then tested in the two tasks. Half of the subjects from each group were tested in the spatial task before the conditional task, and half of the animals received testing in the opposite order. Because of a mechanical failure in the shock generator, two to three animals in each group received fewer foot shocks than intended in the fear task. Their data were dropped, and nine additional animals (three per group) were run in this task alone.

T-maze experiments. Rats were first food-deprived to $80 \%$ of their original body weight. Five days before training, rats were handled for 1-2 


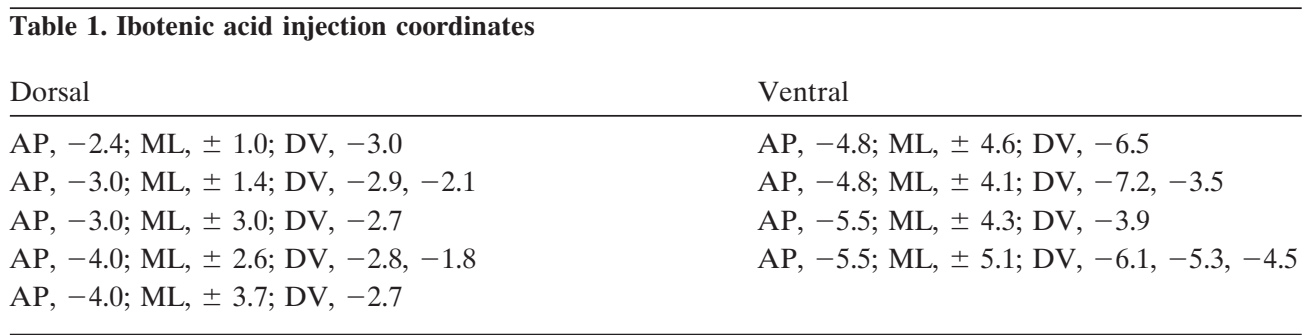

AP, Anteroposterior; ML, mediolateral; DV, dorsoventral.

min each day and given four whole Froot Loops (FLs) per day for $2 \mathrm{~d}$ in their home cages to accustom them to eating FLs. On the third day, rats were brought to the training room one at a time and placed in the start box $(24.7 \times 10.8 \times 13.3 \mathrm{~cm})$ of the T-maze without the guillotine door. The T-maze was made of $5 \mathrm{~mm}$ black Plexiglas, and the roof was covered with clear Plexiglas over the start and goal boxes, whereas the rest of the maze was covered with $5 \mathrm{~mm}$ wire mesh squares. Each arm of the $\mathrm{T}$-maze was $50.8 \mathrm{~cm}$ long. FLs were located along the floor of the T-maze and in the reward cups of each goal box. Each rat was allowed to roam freely in the T-maze for 20 min before the next rat was run. The maze and floor were cleaned after each rat's session.

On day 4, five or six FLs were placed in the goal boxes, and three FLs were placed in the reward cups. Each rat was placed in the start box with the guillotine door closed, and after $4 \mathrm{sec}$, the door was opened and the rat was allowed to roam until reaching a goal box, at which point the door was closed. The rat was removed from the goal box after eating an FL and placed back into the start box, and the procedure was repeated. The procedure was repeated until $20 \mathrm{~min}$ had elapsed.

Training began on day 5. Each rat was run on a reinforced alternation schedule according to the procedure described by Thomas (1978). Each rat was rewarded with one FL for entering the arm opposite to the one just visited. The criterion for an arm choice was that all four paws passed the point where the guillotine door would close. The rats were run for six trials a day until they reached a criterion of one or fewer errors on 2 consecutive days. To control for the possibility that the rats were smelling the reward at the end of the arm, the last two trials of each day were not rewarded until the rat reached the correct goal box. This was done by dropping the FL in the reward cup after closing the guillotine door. Performance on these trials did not differ from that on the standard trials.

Once the criterion was reached, the reinforced delayed alternation task began. During this phase, a 5 min delay was added between trials, during which the rat was placed back in its home cage. Subjects were run for six trials per day using this procedure until the criterion of one or fewer errors on 2 consecutive days was reached.

Internal state-shock association task. While half of the rats were being tested in the T-maze, the other half were being trained in the conditioning chamber (81302; Lafayette Instrument Co.). The conditioning chamber $(29 \times 21.5 \times 27 \mathrm{~cm})$ had two side stainless steel walls and two Plexiglas walls comprising the front and back. On the top was a Plexiglas door through which animals were placed into the chamber. The floor consisted of 18 stainless steel bars measuring $5 \mathrm{~mm}$ in diameter with a 1 $\mathrm{cm}$ gap between each bar. A $0.9 \mathrm{~mA}$ electric shock could be administered through the grid floor for $0.5 \mathrm{sec}$. A white Styrofoam cooler $(61 \times 35.6 \times$ $36.8 \mathrm{~cm}$ ) with the bottom cut out was placed over the conditioning chamber. A video camera (CC547; RCA) was mounted on a tripod to record freezing behavior through the Plexiglas door.

In this task, a brief foot shock was delivered in the chamber, conditional on the subject's internal state, i.e., food deprivation level. Rats were placed on a food deprivation schedule such that $24 \mathrm{hr}$ periods of $a d$ libitum food alternated with $24 \mathrm{hr}$ periods of food deprivation. At the end of a $24 \mathrm{hr}$ period, rats were brought down to the well lit training room one at a time and placed in the conditioning chamber for $4 \mathrm{~min}$. Rats in the deprivation-shock (DS) group were given a brief foot shock at the end of 4 min only on those days when they were food-deprived; on nondeprived days they received no foot shock. Animals in the fed-shock (FS) group received foot shock only on those days when they were not deprived. The rats were trained for a total of eight sessions, spaced across $11 \mathrm{~d}$. This schedule prevented foot shocks from alternating across days. The remaining $19 \mathrm{~d}$ were extinction trials in which the rats were maintained on the deprivation schedule and were brought down to the same training room and placed in the chamber but received no shock.
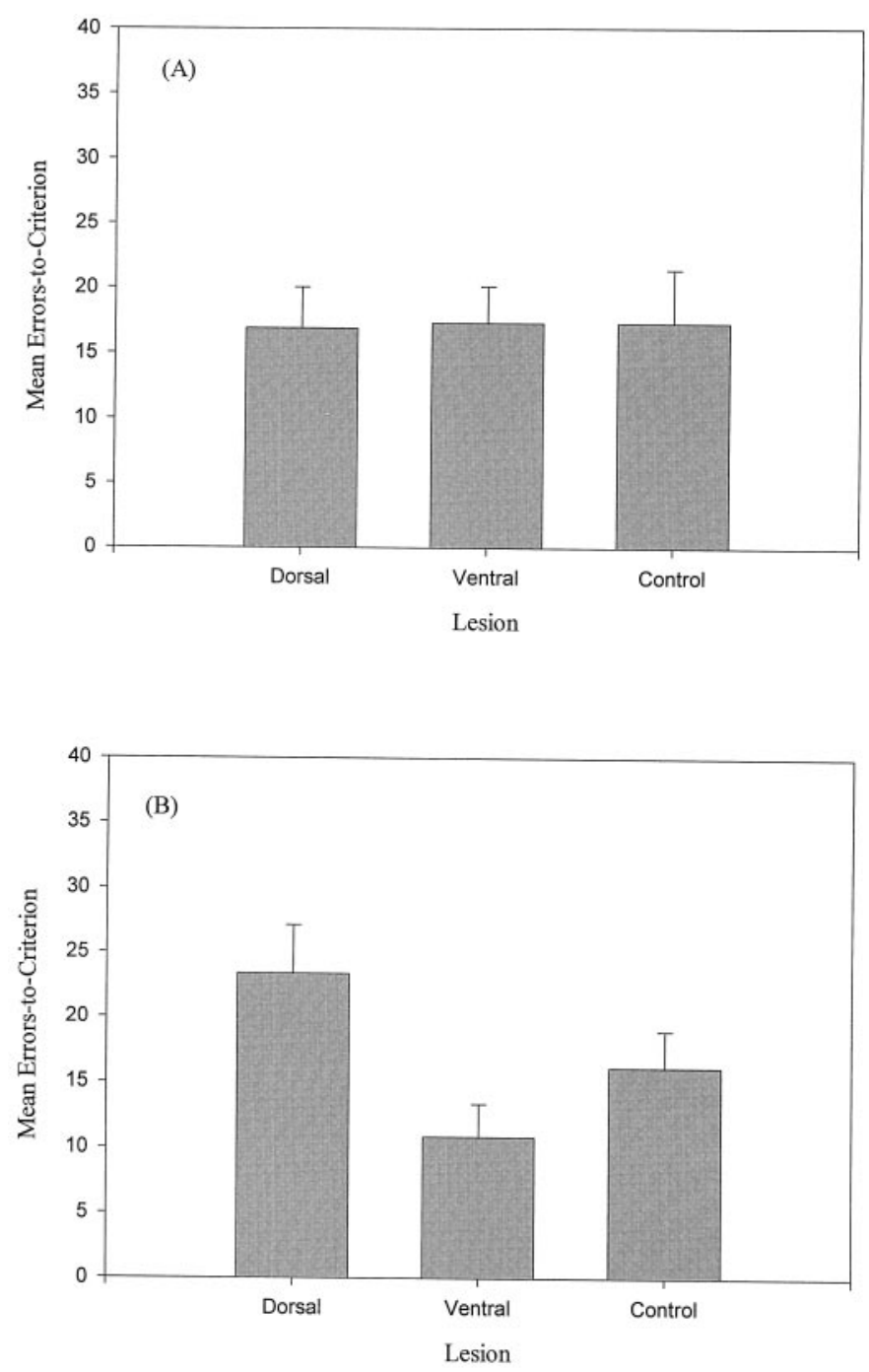

Figure 1. $A$, The effects of $\mathrm{DH}, \mathrm{VH}$, and sham lesions on the zero delay alternation in the T-maze. Bars represent mean + SEM errors to criterion. $B$, The effects of $\mathrm{DH}, \mathrm{VH}$, and sham lesions on delayed alternation in the T-maze. Bars represent mean + SEM errors to criterion.

After this experiment, subjects were trained in an olfactory discrimination task not reported here (Hock and Bunsey, 1997).

\section{RESULTS}

\section{T-maze experiments}

$\mathrm{DH}(n=8), \mathrm{VH}(n=8)$, and sham-lesioned $(n=9)$ rats did not differ in the zero delay training $(p>0.1)$ (Fig. $1 A)$. For the $5 \mathrm{~min}$ delayed alternation task, the dependent measure of errors to 
criterion was evaluated using a one-way ANOVA. For the errorsto-criterion-dependent variable, there was a significant effect of lesion $\left(F_{(2,24)}=4.93 ; p=0.017\right)$, and further a priori tests using a Fisher's least significant difference test found DH [mean $(\mathrm{M})=$ 23.37] made significantly $(p<0.05)$ more errors than both $\mathrm{VH}$ $(\mathrm{M}=10.5)$ and controls $(\mathrm{M}=13.33) . \mathrm{VH}$ and controls were not significantly different from each other $(p>0.1)($ Fig. $1 B)$.

\section{Internal state-conditional task}

For DH $(n=9)$, VH $(n=9)$, and sham-lesioned $(n=8)$ rats, learning was indexed by preferential freezing when in the internal state associated with shock. Freezing behavior was classified as skeletal muscle immobility as defined by Fanselow and Bolles (1979).

Behavior was videotaped and scored by tabulating freezing once every $10 \mathrm{sec}$ during the entire 4 min interval, with a maximum possible score of 24 for a session. The dependent measure used in subsequent analyses was a $\mathrm{d}^{\prime}$ score for a pair of days calculated by subtracting the amount of freezing on the nonshocked day from the amount of freezing on the shocked day, divided by the total freezing score for both days. This was done for each of two pairs of days chosen a priori. Based on the data of Davidson and Jarrard (1993) and our pilot data, we chose for analysis the last $2 \mathrm{~d}$ of training and the third and fourth days of extinction. The first $2 \mathrm{~d}$ of extinction were dropped because of a videotape failure. It was during this block of trials, at the end of training and beginning of extinction, that controls have shown maximal learning, whereas hippocampals have demonstrated clear impairment (Davidson and Jarrard, 1993).

A repeated measures analysis revealed a significant effect of treatment $\left(F_{(2,22)}=3.89 ; p=0.036\right)$ but no interaction between treatment and session $(p>0.1)$. Further analysis between $\mathrm{DH}$ and controls yielded a significant treatment effect $\left(F_{(1,14)}=8.65\right.$; $p=0.011)$, as did an analysis comparing $\mathrm{VH}$ and controls $\left(F_{(1,14)}\right.$ $=4.82 ; p=0.046$ ) (Fig. 2).

In all groups, there was little to no freezing at any point before the first shock. Groups also did not differ in terms of absolute amount of freezing $(p>0.1)$, nor was there an interaction between treatment and session $(p>0.1)$, although numerically $\mathrm{VH}$ froze less than the other two groups (Table 2).

\section{Histology}

Three subjects, two DH and one VH, had little or no apparent damage to the target structure, likely because of blockage of the syringe during surgery, and were dropped before analysis. The remaining subjects in the DH group had substantial DH ablation bilaterally, with minimal damage to overlying cortex and to $\mathrm{VH}$ (Fig. 3). DH rats had an average loss of $60 \%$ of dorsal tissue $(\mathrm{SEM}=7.29)$, comparable with previous studies (Bunsey and Eichenbaum, 1995) with much of the sparing at the rostral and caudal extremes of DH. The volume of $\mathrm{VH}$ in these subjects was $90 \%$ of controls $(\mathrm{SEM}=5.34)$, with most of this $\mathrm{VH}$ loss reflecting shrinkage rather than direct damage. In two of the $\mathrm{DH}$ rats, there was substantial bilateral cortical damage over some of

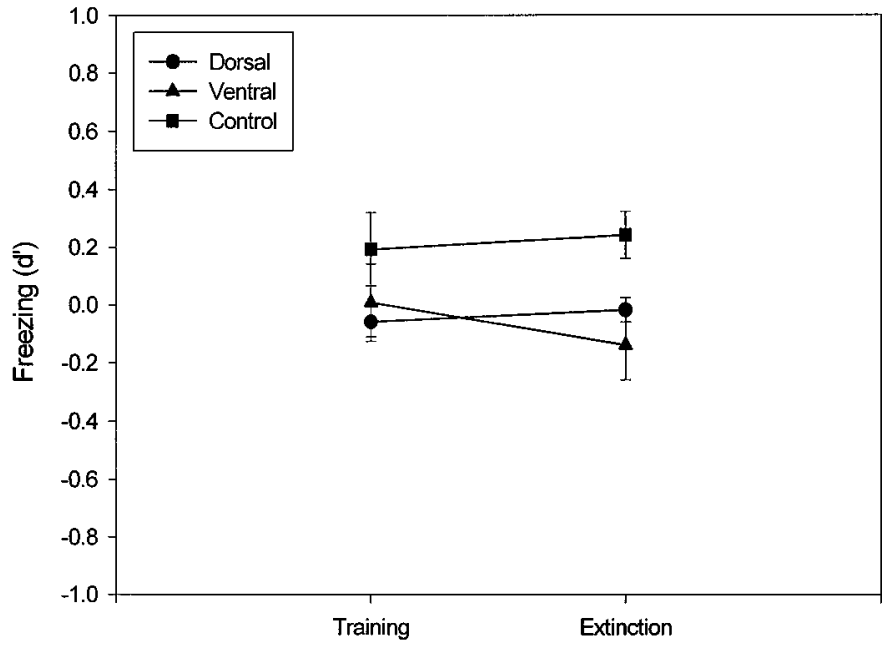

Figure 2. The effect of DH and VH lesions in the internal state-shock association task. Freezing d' scores are plotted with SEs. A score of 0 represents chance performance (i.e., equal freezing in both conditions), whereas scores $>0$ represent greater freezing in the shock-associated state, and scores $<0$ represent less freezing in the shock-associated state.

the lesion (Fig. 3), and in two subjects there was unilateral damage. Most VH subjects had substantial ablation of $\mathrm{VH}$ with little or no apparent damage to DH (Fig. 4). These rats had an average loss of $43 \%$ of $\mathrm{VH}$ tissue $(\mathrm{SEM}=6.04)$. This is somewhat less than the ablation in $\mathrm{DH}$ subjects, consistent with previous reports of sparing of some $\mathrm{VH}$ tissue, especially at the ventral tip of VH (Jarrard, 1989; Bunsey and Eichenbaum, 1995). These subjects also had a shrinkage $(15 \%)$ of DH (SEM = 5.46), again with no apparent disruption of cell layers.

\section{DISCUSSION}

The present results revealed an impairment after $\mathrm{DH}$, but not $\mathrm{VH}$, lesions in reinforced delayed alternation, as was expected based on previous studies (Hughes, 1965; Stevens and Cowey, 1973; Sinnamon et al., 1978; Moser et al., 1993, 1995), and impairments after either lesion in an internal state-conditional task. This latter result provides the first evidence for a learning impairment after specific VH lesions. Together, these findings provide further, but still limited, evidence for functional dissociations along the septotemporal extent of the hippocampus. The impairment in delayed reinforced alternation in the T-maze in rats with $\mathrm{DH}$, but not $\mathrm{VH}$, lesions is consistent with past research using other spatial memory tasks (Hughes, 1965; Stevens and Cowey, 1973; Sinnamon et al., 1978; Moser et al., 1993, 1995) and extends the result to a task different from those used in previous studies. An important advantage of the use of the present delayed alternation task is that hippocampals perform normally at short delays, making it is possible to demonstrate a delay-dependent impairment (O'Keefe and Nadel, 1978) and thus allowing us to attribute any deficit to impaired memory rather than deficits in

\section{Table 2. Mean freezing counts}

\begin{tabular}{|c|c|c|c|c|c|c|}
\hline \multirow{2}{*}{$\begin{array}{l}\text { Lesion } \\
\text { Condition }\end{array}$} & \multicolumn{2}{|l|}{ Dorsal } & \multicolumn{2}{|c|}{ Ventral } & \multicolumn{2}{|c|}{ Control } \\
\hline & Shock & No shock & Shock & No shock & Shock & No shock \\
\hline Mean freeze & 12.40 & 14.50 & 9.55 & 9.40 & 16.00 & 12.50 \\
\hline
\end{tabular}




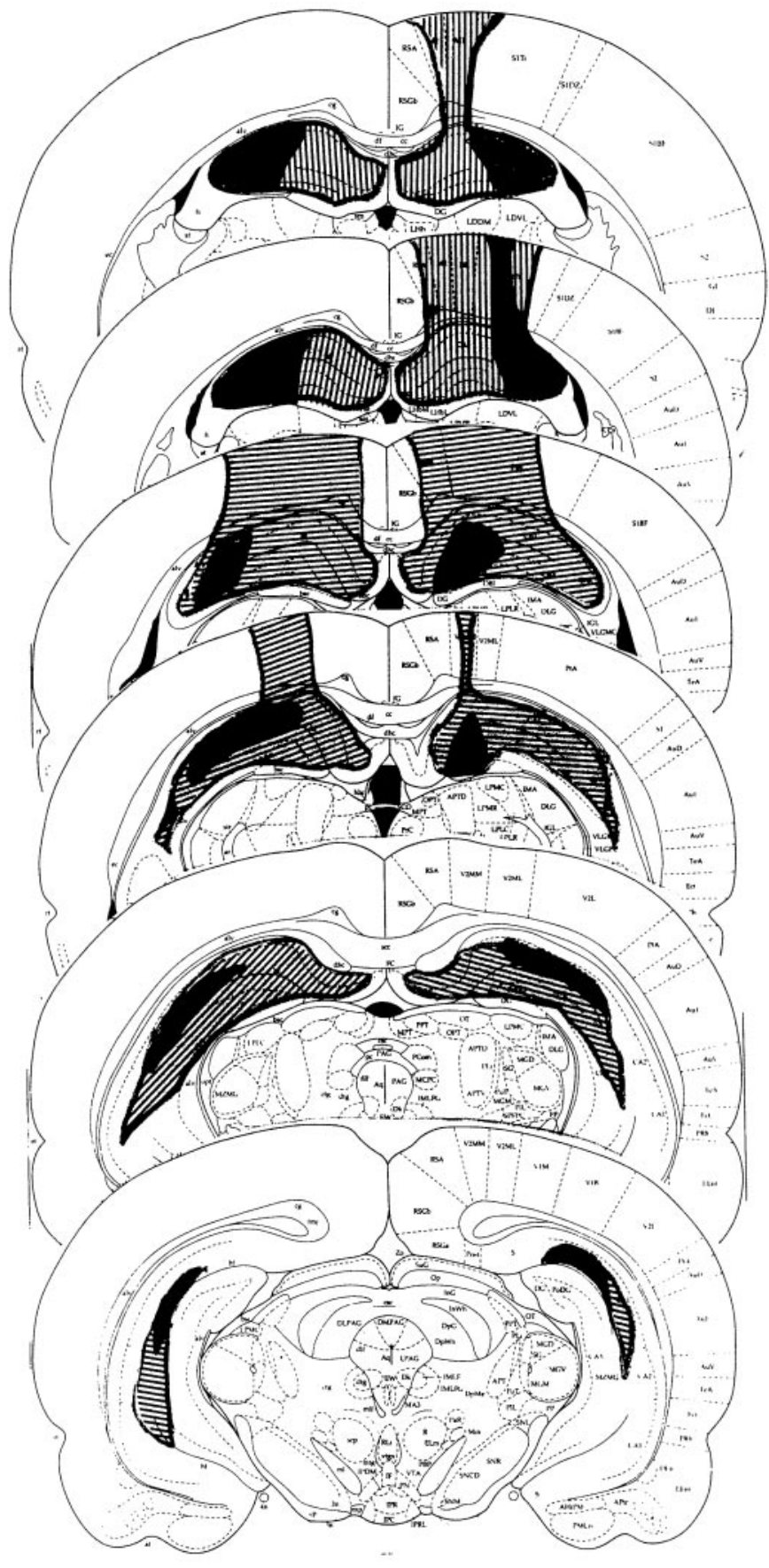

Figure 3. Coronal sections of six slides of DH lesions showing minimal (dark areas) and maximal (shaded areas) damage.

other nonspecific processes. It is not always possible to demonstrate delay dependence in other spatial tasks, because hippocampals are impaired at even the shortest delays. The normal performance of hippocampals with short delays in the T-maze may be attributable to the constraints on responding in this task; subjects can only turn left or right on any trial. In many other tasks, such as the Morris water maze, there are fewer choice constraints. A second important feature regarding the present spatial deficit is that it was observed after a specific neurotoxin-induced lesion (Moser et al., 1995). Specific lesions are especially important in this type of study, because traditional lesions (e.g., electrolytic

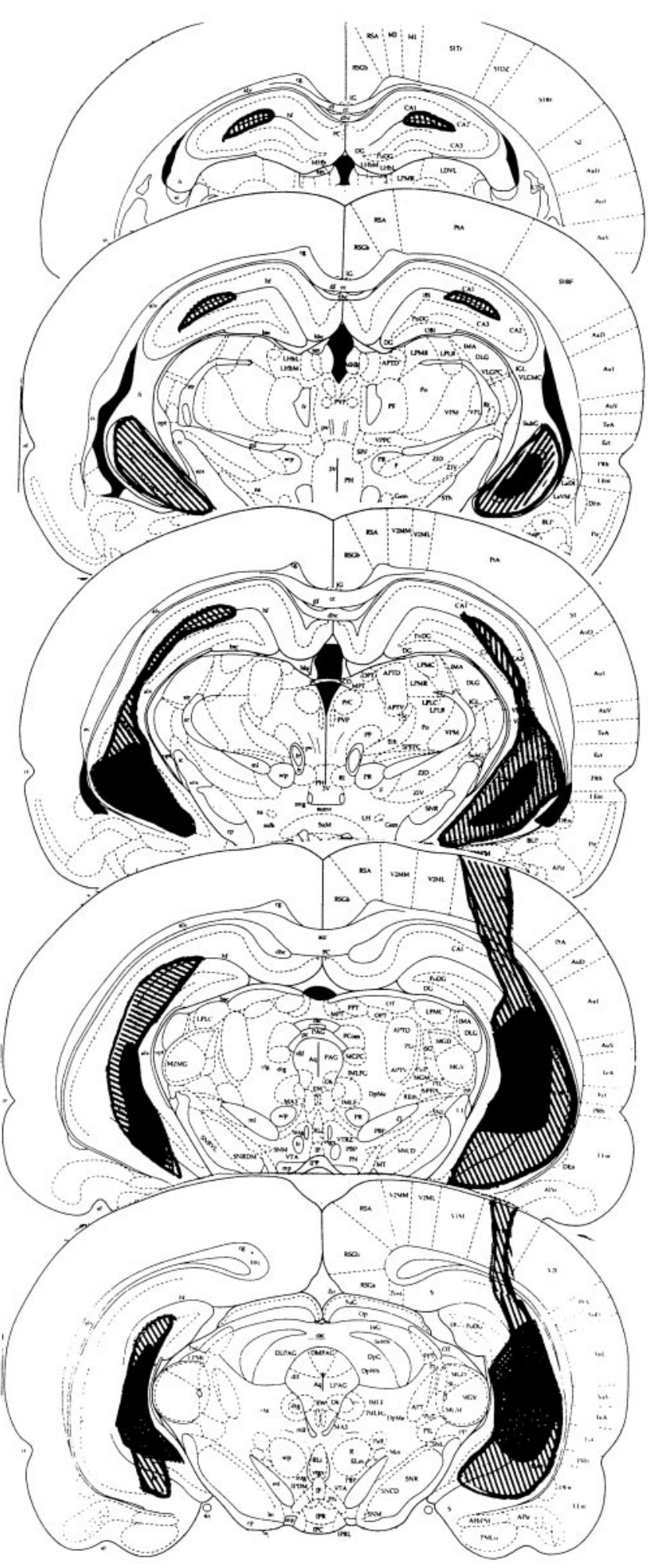

Figure 4. Coronal sections of five slides of VH lesions showing minimal (dark areas) and maximal (shaded areas) damage.

lesions), in destroying fibers of passage, cannot reliably restrict disruption to one-half of the hippocampus. Nonspecificity of lesion may be responsible for the fact that in earlier studies $\mathrm{VH}$ subjects were somewhat impaired in spatial learning, albeit less than DHs (Hughes, 1965; Sinnamon et al., 1978). Although the $\mathrm{DH}$ lesions were larger than the $\mathrm{VH}$ on average, lesion size was 
not likely responsible for the group differences in light of the existing literature (Moser, et al., 1995). These results thus add to the growing body of evidence suggesting a preferential role for DH over VH in spatial memory. As noted above, electrophysiological data provide converging evidence for this framework, showing that place cells are more numerous and spatially selective in the DH than in the VH (Jung et al., 1994; Poucet et al., 1994). Anatomical data are also consistent with this view, indicating that spatial information (i.e., visual and other sensory information) seems to be directed predominantly to $\mathrm{DH}$ in rats (Deacon et al., 1983).

In contrast to the delayed alternation data, the present results revealed impairments after either $\mathrm{DH}$ or $\mathrm{VH}$ lesions in the internal state-conditional task. Earlier studies had demonstrated impairment in VH rats in "probability discrimination" (Stevens and Cowey, 1973) and in extinction in a drink suppression task (Nadel, 1968). These deficits are difficult to interpret given the use of electrolytic lesions and the potential role of hyperactivity in hippocampal subjects as a mechanism for the observed results. The deficits in the present study were consequent to relatively small neurotoxic lesions. It is hypothesized that the present impairment after $\mathrm{VH}$ lesions was attributable to impaired ability to form associations with the internal state-conditional cues. Davidson and Jarrard (1993) provided strong evidence that impaired learning of this task in rats with full hippocampal lesions was critically dependent on the use of internal state as a conditional cue. Hippocampal rats were unimpaired under training conditions that were very similar, with the exception that subjects were tested with an auditory cue-predicting shock (Davidson and Jarrard, 1993). Subjects with specific hippocampal lesions have also been shown to be unimpaired in conditional tasks using olfactory or visual conditional cues (Murray et al., 1993; Bunsey and Eichenbaum, 1996). The use of internal state cues thus seems critical in observing a hippocampal impairment in this type of conditional learning. That this same deficit would be seen in animals with specific VH lesions was predicted given the hypothalamic projections to this region of hippocampus (Kohler et al., 1986). Although speculative, it is possible that this same mechanism may be responsible for the other impairments seen in $\mathrm{VH}$ rats (Nadel, 1968; Stevens and Cowey, 1973). For example, Stevens and Cowey (1973) found VH subjects to be impaired in a situation in which they were required to learn relative rates of reinforcement in two arms of a T-maze in which one arm was rewarded $70 \%$ of the time, and the other was rewarded $30 \%$ of the time. Performance in this task would require a comparison of memories of reinforcement histories in the two arms. Internal states would constitute a large component of these memories.

It is unclear why conditional tasks using internal states as cues would be more vulnerable to hippocampal damage than conditional tasks using other sensory modalities. This difference is most likely attributable to neuroanatomical differences among the various sensory modalities. Specifically, information from most sensory modalities converges in perirhinal and entorhinal cortices before reaching the hippocampus (Deacon et al., 1983). These parahippocampal areas may be sufficient as a substrate for conditional learning, either within or across sensory modalities, after hippocampal damage (Eichenbaum and Bunsey, 1995; Gluck and Myers, 1995). It is possible that the critical information about internal states does not first go through perirhinal and entorhinal cortex but rather is carried within the projection from hypothalamus to $\mathrm{VH}$; $\mathrm{VH}$ lesions would thus prevent this information from converging with other sensory information and cause a conditional learning impairment.

Finally, it is unclear why DH lesions caused an impairment in the internal state-conditional task. One possibility is that both DH and $\mathrm{VH}$ are critical for the processing of internal states. A second possibility is that acquisition of the internal state-conditional task used here requires processing of both internal and external contextual cues. Davidson and Benoit (1996) have recently reported that external context does play an important role in learning this task. Specifically, subjects learn not merely that a particular internal state predicts shock but rather that an internal state experienced in a particular external context (i.e., the conditioning chamber) predicts shock. This spatial-contextual component may account for the impairment after DH lesions. Notably, these data do not show a double dissociation between $\mathrm{DH}$ and $\mathrm{VH}$, and as such it remains possible that $\mathrm{DH}$ lesions are simply more disruptive than VH lesions. Performance in the internal stateconditional task may be impaired after either lesion merely because it is more vulnerable to hippocampal damage than to performance in spatial tasks and thus "requires" less total hippocampal disruption. Nonetheless, in conjunction with electrophysiological and anatomical data, the present results seem to strengthen the case that functional dissociations do exist along the septotemporal extent of the hippocampus.

\section{REFERENCES}

Bunsey MD, Eichenbaum H (1995) Selective damage to the hippocampal region blocks long-term retention of a natural and nonspatial stimulus-stimulus association. Hippocampus 5:546-556.

Bunsey MD, Eichenbaum H (1996) Conservation of hippocampal memory function in rats and humans. Nature 379:255-257.

Davidson TL, Benoit SC (1996) The learned function of fooddeprivation cues: a role for conditioned modulation. Anim Learn Behav 24:46-56.

Davidson TL, Jarrard LE (1993) A role for hippocampus in the utilization of hunger signals. Behav Neural Biol 59:167-171.

Deacon TW, Eichenbaum HE, Rosenberg P, Eckman KW (1983) Afferent connections of the perirhinal cortex in the rat. J Comp Neurol 220:168-190.

Eichenbaum H, Bunsey M (1995) On the binding of associations in memory: clues from studies on the role of the hippocampal region in paired-associate learning. Curr Direct Psychol Sci 4:19-23.

Fanselow MS, Bolles RC (1979) Naloxone and shock-elicited feeding in the rat. J Comp Physiol Psychol 93:236-244.

Gluck MA, Myers CE (1995) Representation and association in memory: a neurocomputational view of hippocampal function. Curr Direct Psychol Sci 4:23-29.

Gunderson HJG, Jensen ER (1987) The efficiency of systematic sampling in sterology and its prediction. J Microsc 147:229-263.

Hock Jr BJ, Bunsey MD (1997) Differential effects of dorsal and ventral hippocampal lesions. Soc Neurosci Abstr 23:1958.

Hughes KR (1965) Dorsal and ventral hippocampal lesions and maze learning: influence of preoperative environment. Can J Psychol 19:325-332.

Jarrard LE (1989) On the use of ibotenic acid to lesion selectively different components of the hippocampal system. J Neurosci Methods 29:251-259.

Jung MW, Weiner SI, McNaughton BL (1994) Comparison of spatial firing characteristics of units in dorsal and ventral hippocampus of the rat. J Neurosci 14:7347-7356.

Kohler C, Swanson LW, Haglund L, Wus J (1985) The cytoarchitecture, histochemistry and projections of the tuberomammillary nucleus in the rat. Neuroscience 16:85-110.

Kohler C, Ericson H, Watanabe T, Polak J, Palay SL, Palay V, Chan-Palay V (1986) Galanin immunoreactivity in hypothalamic histamine neurons: further evidence for multiple chemical messengers in the tuberomammillary nucleus. J Comp Neurol 250:58-64.

Moser E, Moser M, Andersen P (1993) Spatial learning impairment 
parallels the magnitude of dorsal hippocampal lesions but is hardly present following ventral lesions. J Neurosci 13:3916-3925.

Moser M, Moser E, Forrest E, Andersen P, Morris RG (1995) Spatial learning with the minislab in the dorsal hippocampus. Proc Natl Acad Sci USA 92:9697-9701.

Murray EA, Gaffan D, Mishkin M (1993) Neural substrates of visual stimulus-stimulus association in rhesus monkeys. $\mathrm{J}$ Neurosci 13:4549-4561.

Nadel L (1968) Dorsal and ventral hippocampus lesions and behavior. Physiol Behav 3:891-900.

O'Keefe J, Nadel L (1978) The hippocampus as a cognitive map. Oxford: Oxford UP.
Poucet B, Thinus-Blanc C, Muller RU (1994) Place cells in the ventral hippocampus of rats. NeuroReport 5:2045-2048.

Risold PY, Swanson LW (1996) Structural evidence for functional domains in the rat hippocampus. Science 272:1484-1486.

Sinnamon HM, Freniere S, Kootz J (1978) Rat hippocampus and memory for places of changing significance. J Comp Physiol Psychol 92:142-155.

Stevens R, Cowey A (1973) Effects of dorsal and ventral hippocampal lesions on spontaneous alternation, learned alternation, and probability learning in rats. Brain Res 52:203-224.

Thomas G (1978) Delayed alternation in rats after pre- or postcommissural fornicotomy. J Comp Physiol Psychol 92:1128-1136. 